Corrigendum

\title{
Corrigendum to "Morphological and Chemical Properties of Particulate Matter in the Dammam Metropolitan Region: Dhahran, Khobar, and Dammam, Saudi Arabia"
}

\author{
Bassam S. Tawabini $\left(\mathbb{D},{ }^{1}\right.$ Taoreed T. Lawal, ${ }^{1,2}$ Abdulaziz Al-Shaibani ${ }^{1}{ }^{1}$ \\ and Ashraf M. Farahat $\mathbb{D}^{3,4}$ \\ ${ }^{1}$ Geosciences Department, King Fahd University of Petroleum and Minerals (KFUPM), Dhahran 31261, Saudi Arabia \\ ${ }^{2}$ Department of Industrial Hygiene, College of Engineering, West Virginia University, Morgantown, WV 26505, USA \\ ${ }^{3}$ Physics Department, King Fahd University of Petroleum and Minerals (KFUPM), Dhahran 31261, Saudi Arabia \\ ${ }^{4}$ Department of Physics, Faculty of Science, Alexandria University, Alexandria, Egypt
}

Correspondence should be addressed to Ashraf M. Farahat; farahata@kfupm.edu.sa

Received 13 May 2018; Accepted 16 May 2018; Published 9 August 2018

Copyright (c) 2018 Bassam S. Tawabini et al. This is an open access article distributed under the Creative Commons Attribution License, which permits unrestricted use, distribution, and reproduction in any medium, provided the original work is properly cited.

In the article titled "Morphological and Chemical Properties of Particulate Matter in the Dammam Metropolitan Region: Dhahran, Khobar, and Dammam, Saudi Arabia" [1], the name of the third author was given incorrectly as Abdulaziz Shaibani. The author's name should have been written as Abdulaziz Al-Shaibani. The revised authors' list is shown above.

\section{References}

[1] B. S. Tawabini, T. T. Lawal, A. Shaibani, and A. M. Farahat, "Morphological and chemical properties of particulate matter in the Dammam metropolitan region: Dhahran, Khobar, and Dammam, Saudi Arabia," Advances in Meteorology, vol. 2017, Article ID 8512146, 9 pages, 2017. 

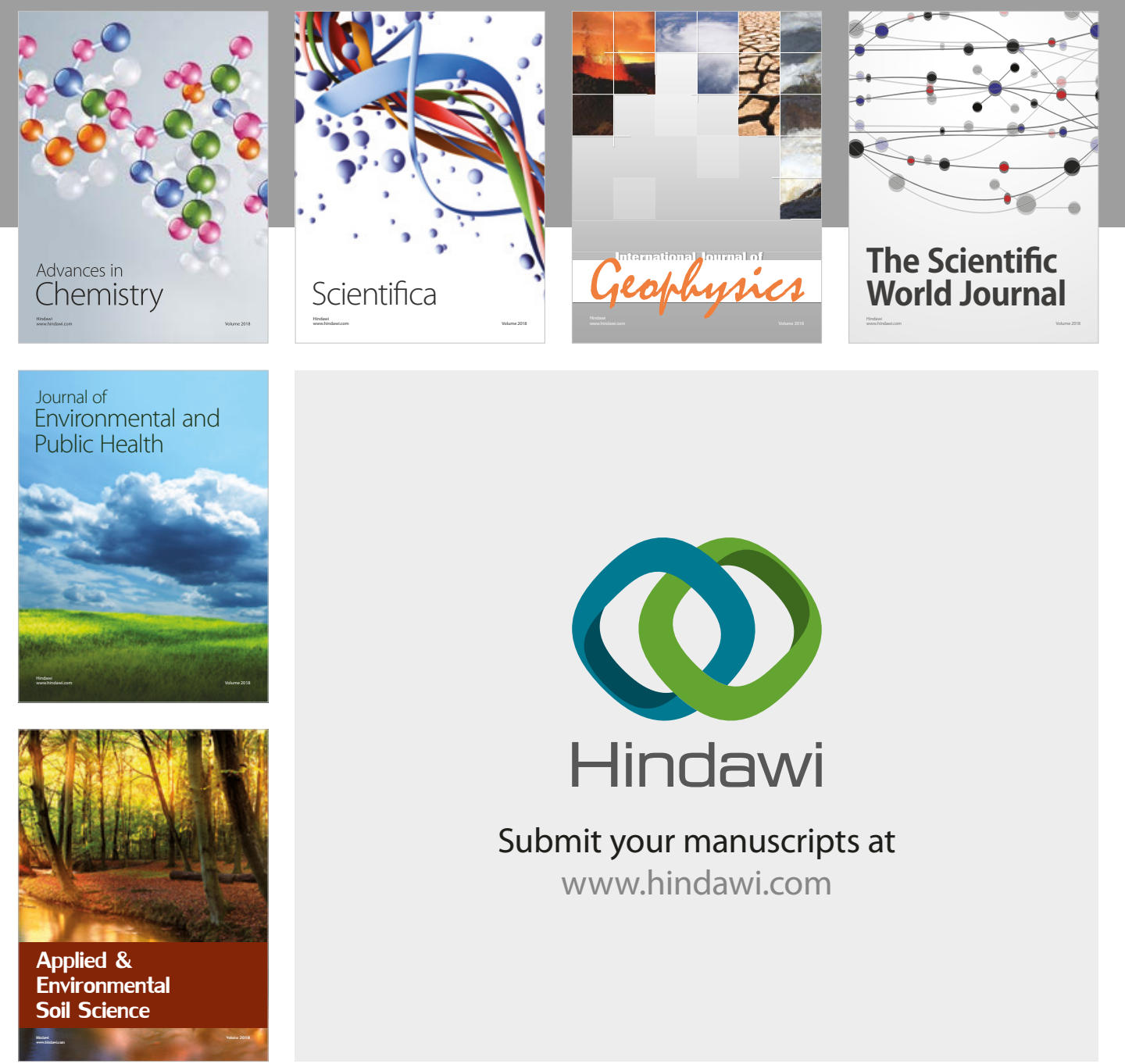

The Scientific

\section{World Journal}
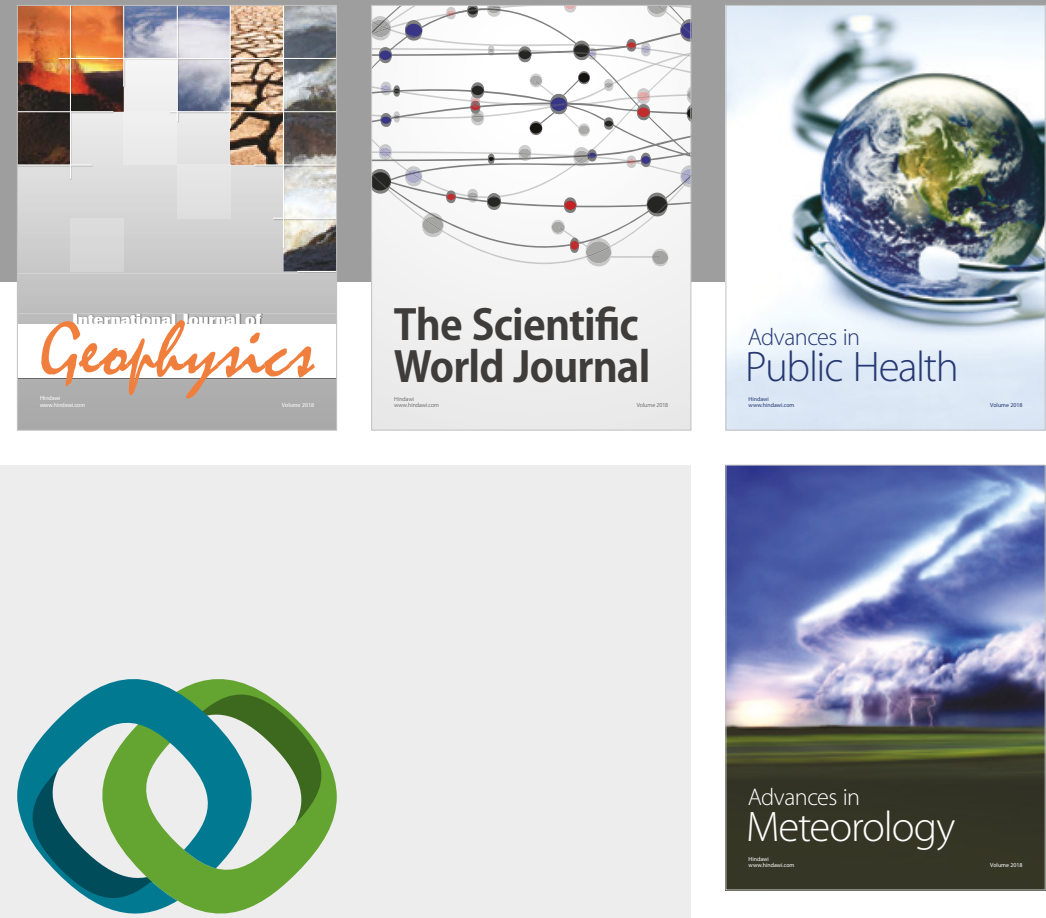

Advan

Public Health

\section{Hindawi}

Submit your manuscripts at

www.hindawi.com
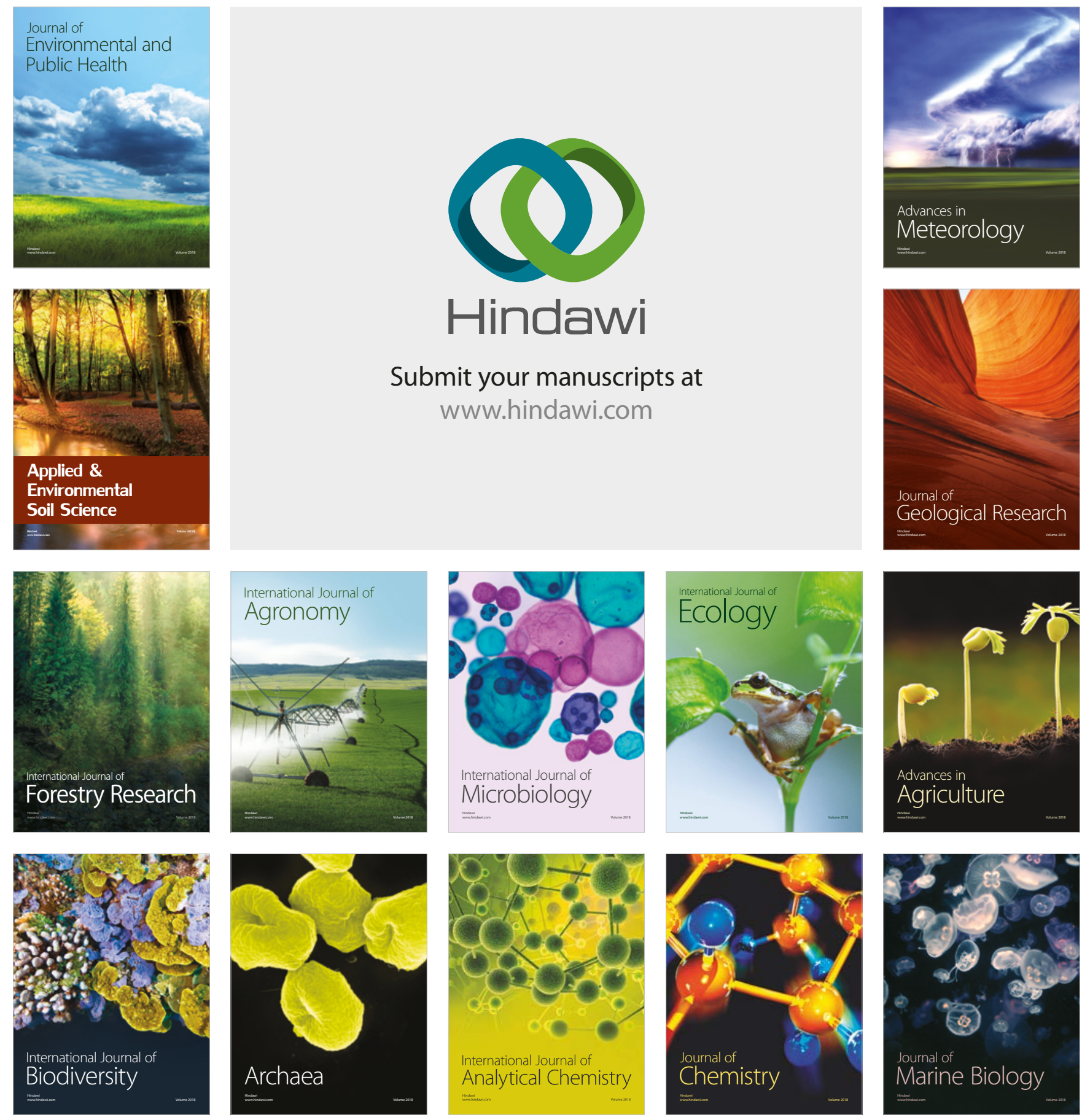